He was commenced on an alcohol detoxification regime and further investigation of his hypokalaemia was attempted. During the course of his admission he confided to a member of staff that he had been vomiting on an almost daily basis for 25 years, following criticism of his weight by his father. He admitted bingeing (often daily), but denied the use of diuretics or laxatives.

Following this he received some cognitive psychotherapy and his depressive symptoms were treated with a serotoninspecific reuptake inhibitor antidepressant. On this regime his depressive and bulimic symptoms improved dramatically. His clinical chemistry returned to normal.

Regional Addiction Unit

KAREN WilliamS

All Saints Hospital

Lodge Road

Birmingham B18 5SD

\section{Anorexia nervosa: forced feeding and the law}

SIR: In their recent article about compulsory treatment for anorexia nervosa (Journal, May 1993, 162 679-680), Drs Tiller et al seem to assume that forced feeding under Section 3 of the Mental Health Act (MHA) 1983 is legal. We found that the law on this matter is by no means straightforward.

The patient, a 29-year-old woman, once a successful professional, lived at home with her elderly parents. She was diagnosed as having anorexia nervosa five years ago and did not respond to attempts to help her, never engaging with treatment offered by a variety of specialists in eating disorders. When her weight was $28 \mathrm{~kg}$, while in a medical ward, the consultant psychiatrist successfully recommended treatment under Section 3 of the MHA 1983. She offered little resistance to the insertion of a nasogastric tube, to taking chlorpromazine $(100 \mathrm{mg}$, daily), and to a carefully planned re-feeding programme. When she attained a weight of $32 \mathrm{~kg}$ the tube was withdrawn and she was transferred to the relatively comfortable psychiatric ward. However, her condition deteriorated once again and forced feeding needed to be reinstated.

The Court's inherent prerogative power to act on behalf of incapacitated adults was extinguished by statute in the UK in 1959. Although the common law has evolved to plug this gap, its powers are limited to making declarations of legality in individual cases, offering general guidelines and suggesting procedural steps to be followed (Lancet, 1993). There is a current lacuna in case law concerning adult anorexics refusing treatment ( $\operatorname{Re} \mathrm{T}$ (Adult) Refusal of Medical Treatment (1992, 4 All ER, 649)).

As the patient was refusing the insertion of a nasogastric tube, the hospital applied for two declarations. The first concerned the giving of treatment by way of artificial feeding as being lawful treatment. The second, that it was lawful treatment within Section 63 of the MHA 1983. Our medical opinion was that the patient did not have the capacity to consent as she seemed unable to appreciate the consequences of further starvation.

The judge ruled that the hospital was entitled to both declarations that it had sought. The patient was considered to lack the capacity to consent. The judge specified that "on the evidence, anorexia nervosa was a mental illness and in those circumstances, provided the treatment that was asked for and which the patient was refusing was the treatment for the mental illness from which she suffered, then the hospital was entitled not only to the declaration they sought in common law but also to the declaration as to the effect of the evidence on the statute". He remarked, however, that had the patient made an advance directive about forced feeding, the outcome might have been different (Brahams, 1993).

The judge's opinion about forced feeding and Section 63 of the MHA 1983 was categorical. He clearly stated that on the evidence "there is no room for argument that the introduction and the maintenance of compulsory feeding does form part of the treatment of the mental illness of anorexia nervosa" and that the prerequisites of Section 63 were met in our case. He also quoted Section 145 of the MHA 1983; "Medical treatment includes nursing and also includes care, habilitation and rehabilitation under medical supervision."

The proceedings did not help the patient. They had eroded further the poor therapeutic relationship and she continues to struggle with her life-threatening condition.

\footnotetext{
LANCET (1993) Mental incapacity and medical treatment. Lancet, 341, 1123-1124.
}

Brahams, D. (1993) Medicine and the law. Lancet, 341, 1143-1144.

Broadgreen Hospital NHS Trust

Colin Lanceley

Thomas Drive

Liverpool L14 3 LB

Scott Clinic

RAY TRAVERS

Rainhill Road

St Helens

\section{Panic disorder with agoraphobia}

SIR: Lelliott \& Marks(1988) previously claimed there was "massive evidence" that "exposure" was a specifically effective intervention for the reduction of 
panic. Therefore, Marks et als findings (Journal, June 1993, 162, 776-787) that exposure therapy, with or without alprazolam, is no better than placebo and relaxation in reducing panic is of interest. Since Marks et al affirm that relaxation is only a credible psychological placebo, the failure of exposure to serve as a specific anti-panic measure is evident.

However, this apparent confirmation of my views (Klein, 1988) is somewhat mitigated by the fact that in this study alprazolam also was of no benefit against panic. Marks et al believe this impugns the value of alprazolam, but to others (Spiegel et al, Journal, June 1993, 162, 788-789) it calls the validity of his study into question. Unusual treatment findings are usually due to unusual samples. Marks et al state that at week 0 , of the 144 intent to treat cases, the mean number of major panics per week was 7.4 with a standard deviation of 11 . Since the standard deviation far exceeds the mean, it is possible that approximately $50 \%$ of the sample had no major panic attacks at all when entering the trial. We would appreciate it if Marks et al would provide the baseline frequency distributions of major and spontaneous panic attacks for the entire sample of 154 patients, as well as the 144 intent to treat cases. It could be illuminating concerning sample composition.

The authors use analyses of covariance, but apparently never do the necessary preliminary analysis for heterogeneity of slope. This would have spoken directly to the relevance of initial clinical status to treatment outcome. The use of post hoc comparisons, "controlled for experiment-wise error due to multiple comparisons" is also dubious, as it leads to an unnecessarily insensitive test for treatment differences. We have discussed both these crucial issues recently (Klein \& Ross, 1993).

KLEIN, D. F. (1988) The cause and treatment of agoraphobia. In reply. Archives of General Psychiatry, 45, 389-392.

- \& Ross, D. C. (1993) Reanalysis of the National Institute of Mental Health Treatment of Depression Collaborative Research Program General Effectiveness Report. Neuropsychopharmacology, 8, 241-252.

Lelliott, P. \& MARKS, I. (1988) The cause and treatment of agoraphobia. Archives of General Psychiatry, 45, 388-389.

Columbia University

DONALD F. KLEIN

College of Physicians and Surgeons

New York

NY 10032, USA

Authors' REPLY: Dr Klein seems to have missed key points in our paper (Journal, June 1993, 162, 776-787) and in our replies to Spiegel et al and Klerman et al (Journal, June 1993, 790-794;
795-796): “... exposure therapy, with or without alprazolam, is no better than placebo and relaxation in reducing panic". In our study, exposure was twice better than alprazolam in reducing most problems of panic disorder with agoraphobia, and even more so compared with placebo. Like other symptoms, panic also improved markedly with exposure, but unlike other symptoms, panic also improved markedly with placebo and with alprazolam. In any case, both patients' and clinicians' independent global ratings of improvement correlated with reduction not in panic but in avoidance.

"Unusual treatment findings are usually due to unusual samples." Our findings were not 'unusual', and in fact agree with results from previous multicentre studies, for example Upjohn Phases I and II. Firstly, those studies also found a good response of panic symptoms to placebo, with no drug effect (not even for imipramine, which Dr Klein has long espoused for panic) on more complete analyses. Placebo is so effective for panic (as opposed to other) symptoms that no treatment does significantly better, whether it is alprazolam, imipramine, or exposure. Secondly, the previous studies also found a huge variance for panic measures.

These two findings are common in the literature and make panic problematic as an outcome measure. Such problems do not beset other measures such as avoidance, anxiety, depression, work and social disability. Dr Klein's belief that panic is the key to panic disorder with agoraphobia may need reconsideration.

"It is possible that approximately $50 \%$ of the sample had no major panic attacks at all when entering the trial." As we wrote, all our patients met DSM-III panic and other criteria for panic disorder at trial entry, including "at least one three-symptom panic a week, and at least two past unexpected threesymptom panics". We pointed out that our patients had even more panics at baseline than did patients in previous multicentre studies, and that Spiegel et al (Journal, June 1993, 162, 788-789) were mistaken in writing that our sample differed from others with respect to baseline depression. Brevity precludes publication here of all the data Dr Klein asks for, but we would be glad to send these to him.

"Call for yet more analyses." In the London/ Toronto study the results were similar with a wide variety of analytic methods. Apart from ANCOVA, MANCOVA and post-hoc analyses (whether or not controlled for experiment-wise error), the same pattern emerged for: effect size, survivor analyses and inspection of means, and across sites, raters, measures (including ten different criteria of panic symptoms), and intent-to-treat and evaluable patients. 